\title{
Laser Applications in European Automotive Manufacturing: Historical Review and Recent Trends*
}

\author{
Dirk PETRING ${ }^{* *}$
}

\section{Introduction}

It is one of the big challenges for a manufacturing technology: to be approved for serial automotive production. Stringent production cycles as well as high quality, safety and environmental standards and keen price competition make automobile industry to one of the toughest sectors in modern industry. Laser material processing started to receive attention as a manufacturing option and an innovative technique for new automotive product and production solutions 30 years ago. Looking back, automobile industry with its high demands on reliability, productivity, profitability and innovation was and still is one of the big drivers and beneficiaries of the continuous improvements of laser sources, systems and processes.

This article shall demonstrate that the special capabilities of laser supported manufacturing technologies very well cope with the persistent trends in auto industry, such as lighter weight to be achieved by new materials, designs and processes, and more frequent model changes with multifaceted variants to be accomplished by flexible production lines. It gives a historical review on milestones and highlights of laser cutting and joining applications in Europe's auto industry by quoting more than 100 industrial examples, in order to pay tribute to pioneer work and to present recent developments and progress in laser manufacturing of automobiles.

\section{Laser Cutting}

\subsection{Discovery of $2 \mathrm{D}$ and $3 \mathrm{D}$ laser cutting potential} In the early seventies of the last century, the possibility of using focussed laser light for flexible cutting of metal sheets fascinated engineers at Ford (Cologne, Germany). They installed a $\mathrm{CO}_{2}$ laser system of Messer-Griesheim for

*Received 2004, 9, 1

** Fraunhofer-Institute for Laser Technology ILT, Aachen, Germany 2-dimensional prototype cutting of car body components in 1974. Also for small batches during pre-production, when the design is still in progress or the conventional cutting tools are not yet ready, this proved to be very cost efficient and offered a fast access to high quality parts already in an early product stage.

Five years later, in 1979, Seica, an Italian supplier for automobile companies started 3-dimensional cutting of plastic dashboards with a five-axis Prima Industrie system called "ZAC". This system overcame the still limited beam quality of those former $\mathrm{CO}_{2}$ lasers and their resulting beam divergence by combining an $x-y$ table for workpiece movement and a z-axis with two rotary axes for the laser head, in order to minimize beam path variation.

\subsection{Prototyping and customisation at the car manufacturers}

In the eighties many systems followed and in fact, in Europe this was the decade of wide-spread introduction of 2- and 3-dimensional laser cutting in automotive industry. In 1980, BMW (Munich, Germany) operated their first 500 $\mathrm{W} \mathrm{CO}_{2}$ laser gantry system from Messer-Griesheim to cut prototype body parts and 1982 VW (Wolfsburg, Germany) followed with a 3-dimensional laser cutting system. In 1983, Austin Rover (Coventry, UK) started to trim prototype body panels with a $2 \mathrm{~kW} \mathrm{CO}$ laser manufactured by Control Laser combined with a 5 -axis gantry. During 1984, also Volvo (Goteborg, Sweden), Fiat (Turin, Italy) and Mercedes Benz (Sindelfingen, Germany) installed laser cutters. In 1985 Alfa Romeo (Italy) put a flexible laser plant with $3 \mathrm{CO}_{2}$ lasers and 5 cutting units into operation. VW decided in 1986 to customise apertures for their right-hand drive Golf with a Ferranti $450 \mathrm{~W} \mathrm{CO}_{2}$ laser and a Robomatix 3-D cutting system. Prototyping, customisation and small batches are the main automotive laser cutting applications in those years.

2.3 Increasing range of applications at the subcontractors

Sheet metal as well as plastic parts and wooden interiors are cut by lasers. Not only the automobile companies but also their suppliers are installing laser systems for 3-dimen- 
sional cutting. Kaliko (Goeppingen, Germany, 1984) cuts PVC ceilings, Pininfarina (Turin, Italy, 1986) shortens the floor pan for the cabriolet version of a Cadillac, Benteler (Paderborn, Germany, 1987) cuts apertures in wheel suspensions and Inoplast (Lyon, France, 1987) cuts fibreglassreinforced plastic parts for vehicle exteriors.

\subsection{First serial application in the body shop}

The first laser cutting system installed in the body shop for serial production is operated by Renault (Sandouville, France) in 1988. The 5-axis Renault-automation system customises rear window wiper mounting holes, body side light holes and seat belt mounting holes with a $\mathrm{CO}_{2}$ laser in the body line for the R25.

\subsection{Diversification of $\mathrm{CO}_{2}$ laser cutting}

In the nineties power levels increase, beam quality improves and the applications diversify. In 1990 Ford cuts apertures into the underbody of the Transit vans with $\mathrm{CO}_{2}$ laser robots from Robomatix and BMW cuts holes in the steering column tube of the $850 \mathrm{i}$ with a $\mathrm{CO}_{2}$ laser system of Wegmann-Baasel. A very innovative approach is introduced 1991 by Mercedes-Benz (Sindelfingen, Germany) with a system of Held Lasertechnik. In order to achieve an optimum edge preparation and fit-up for laser welding the C-pillar to the roof extension of the S-type cars, the edges of both components are first laser cut with a $2.5 \mathrm{~kW}$ $\mathrm{CO}_{2}$ laser from Trumpf. The subsequent butt joint welding is performed with the same system (see also section "Laser Joining" in this article).

\subsection{First Nd:YAG laser cutters}

Citroen starts the first serial 3-dimensional body-in-white application of a Nd:YAG laser on-line in 1992, when they cut the rear wheel houses of the AX GTI. They operate a pulsed $450 \mathrm{~W}$ laser from Cheval for trimming the wheel houses in order to attach extensions on the sports model of the AX. One year later, Lumonics installed their $500 \mathrm{~W} \mathrm{cw}$ Nd:YAG lasers at Ernst and Gillet, both Germany, for cutting of exhaust system components, and at Motor Panels (Coventry, UK) for trimming Rover body panels.

\section{7 $\quad \mathrm{CO}_{2}$ laser cutting of hydroformed parts}

Nevertheless, in the nineties the $\mathrm{CO}_{2}$ laser is still dominant also in 3-dimensional cutting in Europe. For example, Peugeot (Sochaux, France) cuts various body components and panels with 10 Prima Industrie 5-axis systems equipped with Rofin-Sinar $\mathrm{CO}_{2}$ lasers since 1995. And also the first laser cutting of hydroformed parts in serial production started in Europe 1998 at VW (Braunschweig, Germany) with a $\mathrm{CO}_{2}$ laser. Hydroforming creates hollow metal structural parts from a tubular element that is 3dimensionally shaped inside a mould by fluid under pressure. The number of mouldings required is reduced, and one part replaces several. High stiffness, strength and structural integrity as well as lighter weight and less distortion are important properties. Hydroformed parts are used for load-bearing structural elements and their advan-

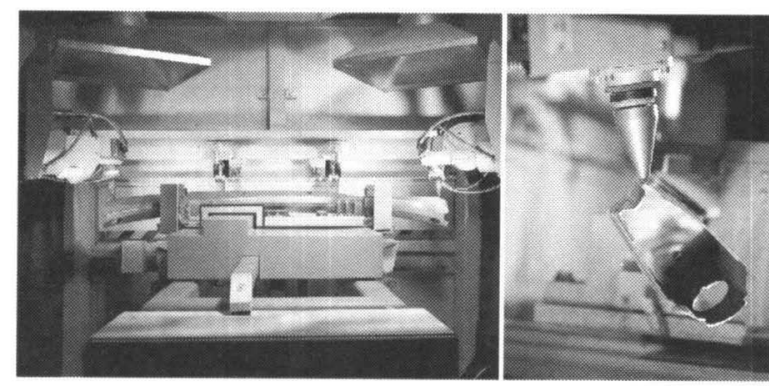

Fig. 1 Cutting hydroformed cross members of the aluminium body front end of the BMW 5 and 6 series with a dual head cantilever system from Schuler-Held Laserstechnik. equipped with two Rofin $2 \mathrm{~kW}$ Slab $\mathrm{CO}_{2}$ lasers (source: Schuler-Held Lasertechnik)

tages have first been recognized by US manufacturers for the frame structures of trucks and SUVs (Sport and Utility Vehicles), which are very popular in the US. While umpteen of $\mathrm{Nd}$ :YAG laser robots have already been installed in North-America for cutting these parts, VW engineers decide in 1998 to use a $2.2 \mathrm{~kW}$ PRC $\mathrm{CO}_{2}$ laser and a cartesian 5-axis system from Prima Industrie with a splitcabin configuration. The system trims and cuts holes into hydroformed supporting bars and wishbones of the 4wheel-drive Golf with higher accuracy and speed than possible with articulated robots.

Also Tower Automotive (Caserta, Italy) installed a similar $\mathrm{CO}_{2}$ laser system in 2000 for cutting hydroformed parts and recently, in 2003, BMW put a special dual head cantilever system from Schuler-Held Lasertechnik into operation, equipped with two $2 \mathrm{~kW} \mathrm{CO}$ slab lasers from Rofin (fig. 1). This system is cutting the hydroformed cross members for the aluminium body front end of the BMW 5 and 6 series.

\section{$2.82 \mathrm{D}$ blank cutting with $\mathrm{CO}_{2}$ lasers}

Beside hydroformed parts and other 3-dimensional applications, also 2-dimensional cutting of automotive blanks is still a growing laser business. More variants and smaller batches of identical parts make conventional tooling increasingly uneconomical. This is the reason, why Alcan, a German Aluminium supplier, operates four Trumpf flat sheet cutters since 2002 in their Nachterstedt plant. Each one is equipped with a $4 \mathrm{~kW} \mathrm{CO}$ laser and automated by two industrial robots, in order to cut serial aluminium blanks for deep drawn components of e. g. Opel Vectra, VW Touareg, Porsche Cayenne, Maybach, DaimlerChrysler SL and Jaguar X350.

\subsection{Nd:YAG laser robots on the way}

On the other hand, also in Europe numbers of Nd:YAG laser installations with robots rise increasingly for 3-dimensional cutting. A very special application was introduced by Mercedes-Benz (Sindelfingen, Germany) already in 1994. A $400 \mathrm{~W}$ Nd:YAG laser from Trumpf (then Haas) is coupled with a fiber of $0.4 \mathrm{~mm}$ core diameter to a 6 -axis Kuka robot mounted on a linear unit. The system pro- 


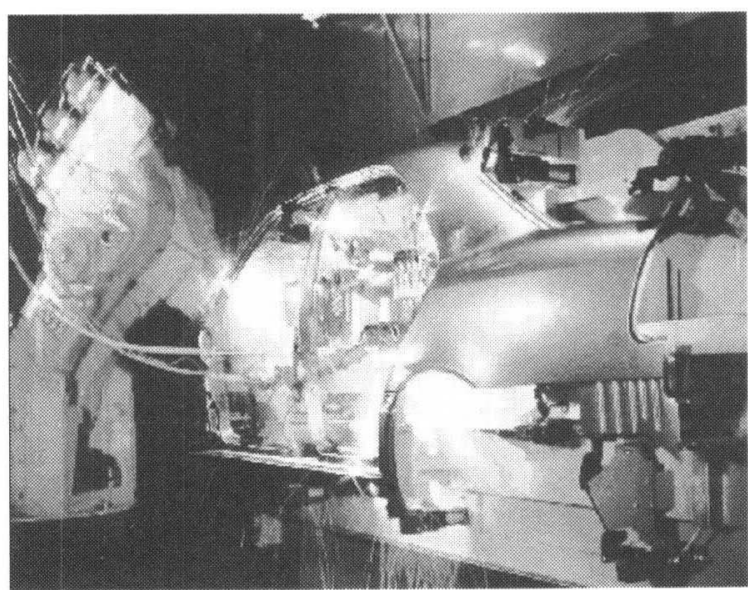

Fig. 2 Cutting replacement parts out of single piece sidewall stampings of the MercedesBenz C series with a 6-axis Kuka robot, fibre-coupled with a Trumpf 400W Nd:YAG laser (source: Trumpf)

duces replacement parts out of single piece sidewall stampings of the C-class (fig. 2). With eleven 3-dimensional cuts, the sidewalls are separated into rear fenders, outer side members, A-pillar outer sections, roof frame outer sections, B-pillars and rocker panels.

Volvo installed an $\mathrm{ABB}$ robot with a $2 \mathrm{~kW}$ Rofin-Sinar Nd:YAG laser and a cutting head from Permanova in 1996 in their Uddevalla plant. The system cuts variants of the C70. The head is exchangeable for a welding head from the same supplier, in order to overlap weld roof to body side. In $1999 \mathrm{Nd}$ :YAG lasers supplied by Trumpf (then Haas) start cutting the hydroformed A-pillar of the 3 series cabriolet at BMW and specific parts of the Scenic at Renault. Fender mounting holes are cut with $\mathrm{ABB}$ robots at Citroen (France) and Volvo (Sweden). The Citroen application involves 30 holes on each body side for front, door and rear fender of the Saxot Sport and is performed in the body line.

Even if some quality problems have been reported occasionally due to robot inaccuracies, Nd:YAG laser robots are inexorably on the way to outplay $\mathrm{CO}_{2}$ laser systems in automotive 3-dimensional cutting applications. The easy handling of the beam and the low adjustment and maintenance requirements of a fibre coupling compared to a beam guiding system with mirrors and beam tubes are substantial arguments. Improved beam qualities due to efficient diode laser pumping of the solid state laser medium and higher accuracy of the robots due to improved architectures, drives and controls, remedy previous drawbacks and support this trend.

\subsection{Combined processing}

Moreover, the wide-spread use of Nd:YAG lasers for welding promotes their combined utilisation also for cutting. Welding edge preparation by laser cutting is one example. On the other hand, after an intermediate or final assembling procedure by laser welding, e.g. in a framing station, precise trimming or aperture cutting on the assembled configuration within the same fixture yields optimum accuracy of the component.

The individual cut-to-length of the front rail in the Golf 5 production of VW, started in 2003, is a recent example of combined processing. It eliminates additional alignment work during final assembly of the mounting plate of the front end by combining a cut-to-length operation and the subsequent weld within one laser robot, carrying both, the cutting and the welding head.

\section{Laser Joining}

\subsection{First welds are circular}

In Europe Fiat (Turin, Italy) pioneered laser welding for the serial production of manual synchronous transmission gears at the end of the seventies. By replacing a conventional brazing process, they could reduce heat input and achieved high part accuracy without post machining. The car driver's benefit was a reduced noise level from the transmission.

The eighties are the decade, when circular welds on small parts of the fuel supply, exhaust and brake systems as well as on engine and power train components are getting established. Easy joint fit-up and the acceptability of a simple rotary axis facilitated the introduction of suchlike applications. Bosch, Germany, started in 1981 with first trials, which later on lead to numerous welding applications on fuel injectors, fuel filters, actuators and sensors (e.g. brake sensors for ABS or lambda probes for catalytic converters). Mass production of these parts profits from the low cycle times achieved with lasers in comparison to conventional processes. Moreover, the low and concentrated heat input of the focussed laser light is an essential benefit for this temperature sensitive type of products. In 1983/84 Mercedes-Benz (Germany) and the German supplier Ina-Schaeffler began to weld cam followers for diesel engines with $\mathrm{CO}_{2}$ lasers, probably the first mass production with lasers in European automotive industry. High productivity, low heat input and low distortion are important features of the application. Moreover, the laser process without filler material eliminated clogging of the oil drill holes, which occurs with the brazing process formerly used. VW and Audi (both Germany) followed in 1985. At that time, also the welding of transmission gear parts, originally started in Italy (see above), was introduced in Germany by VW and in France by Renault. Austin Rover (Coventry, UK) and Ford (Cologne, Germany) entered into gear welding in 1988. Meanwhile, there are innumerable laser welding applications in the power train at car manufacturers and their suppliers, including joints on various types of gears, hubs and shafts. 


\subsection{The history of tailor welded blanks}

The demand for a large-size $3.2 \mathrm{~m}$ long and $1.95 \mathrm{~m}$ wide floor pan out of galvanized steel for a new, completely galvanized body of the Audi limousine was driving Thyssen engineers in 1983 to build the first laser tailored blank welder, in this case joining two sheets with still identical properties. The corresponding serial production system was put into operation in 1985 . The galvanized sheets were welded in butt joint configuration to large-size blanks in order to overcome the limited coil width capacities of the then available galvanization lines. In 1989 VW (Wolfsburg, Germany) leveraged laser welding of tailored blanks by deciding to use them for the front side members on the Golf 3 . This became the first mass production of tailor welded blanks (TWBs) at ThyssenKrupp in Duisburg-Bruckhausen, Germany. TWBs can be composed of sheets with different thickness, material grade and coating. They reduce the number of parts, tools and processing steps in auto body manufacturing. The utilisation of TWBs reduces weight and costs, optimizes tolerances and improves useful properties (e.g. stiffness, strength, crash safety, corrosion resistance) simultaneously. In other words, they provide an optimised spatial distribution of properties in the completed blank. In 1991 Renault (Douai, France) starts TWB production for the centre pillar of the R19 model, using a 5 kW Rofin-Sinar $\mathrm{CO}_{2}$ laser and a Renault Automation system. Hoesch Platinen GmbH (Dortmund, Germany) followed in 1992, using systems from Held Lasertechnik. The French automobile companies Peugeot and Citroen entered into TWB production in 1993. Typical applications are front side members, pillars, door inner panels, shock tower housings, wheel houses, floor panels and body side inner panels. From the very first, European tailored blanks are mainly produced by subsidiaries of steel companies, the leading ones being ThyssenKrupp, Arcelor, Voestalpine, Corus and Salzgitter (in the order of present TWB market shares). European tailored blanks production amounted to about 780.000 metric tons in 2002. Most systems are equipped with $\mathrm{CO}_{2}$ lasers in the power range between 5 and $10 \mathrm{~kW}$. The latest trend are nonlinear tailored blanks welded with Nd:YAG lasers (fig. 3), first been tackled by ThyssenKrupp in 1999 with 2 welding heads and 2 Trumpf (then Haas) lasers. Additional design options offered by nonlinear seams and the easy and flexible installation of fibre-coupled lasers together with simplified process conditions are promoting these trends. The gap situation with nonlinear TWBs is a special problem to be compensated by precise edge preparation, the use of dual laser spot configurations, laser spot oscillation, cold filler wire or laser-arc hybrid technologies. Also seam tracking, measurement of gap size, closed-loop gap compensation, process monitoring and on-line open-loop and closed-loop quality control are topics of continuing development. Meanwhile, there is an entire family of laser welded tailored products for vehicle

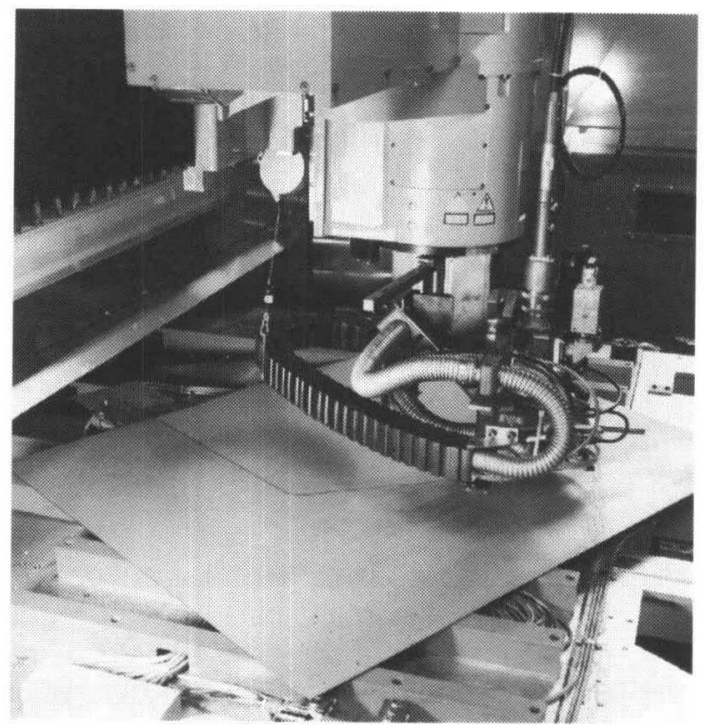

Fig. 3 Welding device, fibre-coupled with a $\mathrm{Nd}$ YAG laser, for non-linear tailored blanks at ThyssenKrupp (source: ThyssenKrupp).

panels, members, frames, and wheels, including tailored tubes, tapered tailored tubes and tailored strips. Currently, beside steel also aluminium TWBs are approaching the market.

\subsection{The pioneers of roof seam welding}

Another milestone, reached in the eighties, is the first laser welding of roof to side frame at BMW (Germany) in 1986. It is the world's first serial laser welding application in the body shop at all. BMW operated a five-axis gantry system from $\mathrm{MBB}$ with a complex sectioned, expensive clamping device, enabling forces of up to $3 \mathrm{kN}$. A $5 \mathrm{~kW}$ Spectra-Physics $\mathrm{CO}_{2}$ laser welded the $380 \mathrm{~cm}$ long roof seams of the 3-series touring car and since 1990 also those of the $850 \mathrm{i}$ model. The main achievements reported were higher stiffness, safe sealing and better appearance of the roof joint.

In 1991, a similar gantry system as at BMW started welding roof to side panel at Volvo (Gent, Belgium) after 4 years of various $\mathrm{CO}_{2}$ and $\mathrm{Nd}$ :YAG laser and robot tests in their pilot plant in Goteborg, Sweden. The production system is equipped with a $6 \mathrm{~kW}$ Rofin-Sinar $\mathrm{CO}_{2}$ laser and a flexible pressure wheel instead of the complex clamping tool described above.

The same year, 1991, another early laser application for joining the roof panel to the roof frame of the body side was realized at Mercedes-Benz (Sindelfingen, Germany) on their S-class limousine. The production system was installed by Held Lasertechnik with a $5 \mathrm{~kW} \mathrm{CO}$ laser from Trumpf. It created $1.8 \mathrm{~m}$ long stitch weld seams on both roof sides with $8 \mathrm{~mm}$ long stitches, in order to enable repair after damage by drilling and replacement in a car repair shop. Each side is clamped with 14 hydraulic clamping segments.

Another variant of laser roof welding was introduced in 
1992 by BMW (Germany), when they started to use a $\mathrm{CO}_{2}$ laser system with an articulated beam arm. One year later, Peugeot (Sochaux, France) entered into roof seam welding with a $5 \mathrm{~kW}$ Rofin-Sinar $\mathrm{CO}_{2}$ laser.

At the same time, Ford (Cologne, Germany) pioneered $\mathrm{Nd}$ :YAG laser welding of roof to side panel on the Scorpio estate wagon. They use a $2 \mathrm{~kW}$ Lumonics source and a Kuka robot. The clamping roller device applies a maximum force of $750 \mathrm{~N}$ in accordance with the body stiffness, which allows to bear this maximum load.

In 1994, Volvo expanded their laser roof seam welding applications by operating a $6 \mathrm{~kW}$ Rofin-Sinar $\mathrm{CO}_{2}$ laser with two Kuka robots in the production of the 850 model in their Torslanda plant. The system was complemented by a second laser in 1997. BMW (Dingolfing, Germany) implemented a production unit with even three robots and three $6 \mathrm{~kW} \mathrm{CO} 2$ lasers (in this case from Trumpf) for welding not only the roof-to-side seams but also the rear window frame of the 5 series since 1996. In addition, also the bulkhead and the trunk lid are welded with $\mathrm{CO}_{2}$ lasers at BMW. In total, $11 \mathrm{~m}$ laser seam length in the 5 series cars are proclaimed by BMW.

\subsection{Body, chassis and closures}

Further pioneer work in laser welding of car components was carried out during the late eighties by Fiat, Italy: the rear door of the Lancia with a $2.5 \mathrm{~kW}$ Spectra-Physics $\mathrm{CO}_{2}$ laser and a 5-axis system from Prima Industrie in 1988 at their Turin plant, and the front motor compartment of the Tipo with a $2.5 \mathrm{~kW} \mathrm{CO}$ laser of Rofin-Sinar and a Comau robot in 1989 at their Cassino plant.

There have been other new applications at the beginning of the nineties, like the welding of motor hood stiffeners of the Astra and the Calibra at Opel, Germany, in 1992. With a $3 \mathrm{~kW} \mathrm{CO}$ laser 4 hoods per minute could be welded. At the same time, the high strength and stiffness of laser welded structures convinced the automotive engineers at Audi (Germany) and Citroen (France) to use $\mathrm{CO}_{2}$ laser welding for chassis parts like frames and suspensions.

\subsection{Combining cutting and welding in the body shop}

Mercedes-Benz (Sindelfingen, Germany) operated in 1991 the first combination of laser cutting and welding within one serial production unit (see also section "laser cutting"). In order to achieve an optimum edge preparation and fit-up for laser welding the $\mathrm{C}$-pillar to the roof extension of the S-type cars, the edges of both components are first laser cut with a $2.5 \mathrm{~kW} \mathrm{CO}$ laser from Trumpf. The subsequent butt joint welding is performed with the same system, designed by Held Lasertechnik. The gap width after laser cutting and clamping is below $0.2 \mathrm{~mm}$, but nevertheless the welding process uses filler-wire to ensure a slight reinforcement of the visual seam on the outer skin parts. It is finished by a grinding process. Finishing work could be significantly reduced by using the laser process. Laser welding replaced the previous MIG- process, which induced much more heat, distortion and overfill.

\subsection{Competition of $\mathrm{Nd}$ :YAG and $\mathrm{CO}_{2}$ laser welding}

During the nineties, continuous-wave Nd:YAG lasers in the $\mathrm{kW}$-range increasingly entered automotive production floors. The motivations are the same as for cutting applications (see above) but with additional advantages because of the easier process adjustment due to the absence of a laser induced plasma, which is created during $\mathrm{CO}_{2}$ laser welding. In Germany, $2 \mathrm{~kW} \mathrm{Nd:YAG} \mathrm{lasers} \mathrm{are} \mathrm{used} \mathrm{at}$ GM-Opel for cuts and welds on the trunk lid of the Opel Omega and at Audi for a $20 \mathrm{~cm}$ long overlap weld at the Cpillar of the A4, both starting in 1994. One year later, Audi started their first roof to side panel welding on the A4 Avant series with a $2 \mathrm{~kW}$ Nd:YAG laser - the second Nd:YAG laser roof seam application after the premiere by Ford in 1993. In 1996, further applications of $2 \mathrm{~kW}$ Nd:YAG laser robots for roof seam welding followed: in Germany at Audi on the A3 series and at VW, Wolfsburg on the Passat, in Italy at Fiat, and in Sweden at Volvo's Uddevalla plant on the C70 (fig. 4), the latter system being equipped with two interchangeable heads - one for welding and one for cutting. Also in 1996, Porsche (Zuffenhausen, Germany) put into operation a $2 \mathrm{~kW} \mathrm{Nd:YAG} \mathrm{laser} \mathrm{robot} \mathrm{for} \mathrm{crimped} \mathrm{hem}$ welds of door inners to outers on the Boxter and the Carrera. The main motivation at Porsche for these laser joints is the significantly improved crash rigidity of the doors.

Beside these Nd:YAG laser operations, there are still new $\mathrm{CO}_{2}$ laser installations: Audi installed one $6 \mathrm{~kW}$ RofinSinar $\mathrm{CO}_{2}$ laser for the roof seam of the A6 series in 1996 in their Neckarsulm plant, using 2 robots with articulated arm beam delivery. In the same year, also Volvo installed a similar system, but with two $6 \mathrm{~kW} \mathrm{CO}$ lasers in their Gent plant. Obviously, the high beam quality and the compara-

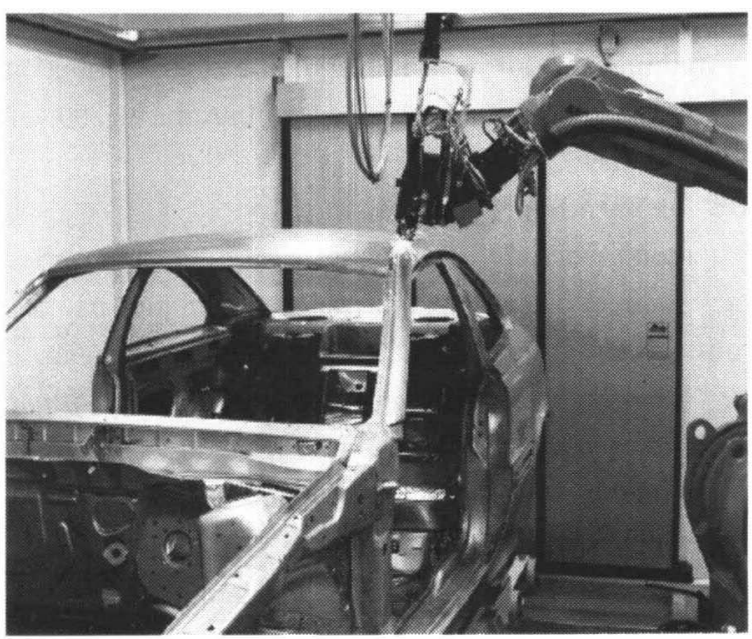

Fig. 4 Welding roof to body side of the Volvo C70 with a 6-axis ABB robot, fibre-coupled with a Rofin 2kW Nd:YAG laser (source: RofinSinar). 
tively lower costs per beam power can still be important arguments for the selection of this laser type, if other advantages of fibre-coupled lasers with shorter wavelength are not of vital interest. However, the shares of $\mathrm{CO}_{2}$ lasers compared to Nd:YAG lasers in body-in-white production began to decrease in the second half of the nineties due to the well known reasons (see above).

\subsection{Early aluminium welding}

There always have been challenges in automotive manufacturing to be accepted by laser technology. One, for sure, was welding of aluminium. Light weight considerations were the driving force. In 1995 Bosch, Germany, was the first to weld aluminium fuel filter housings with a 6 $\mathrm{kW} \mathrm{CO}$ laser. In this application it is a matter of absolutely reliable sealing, accomplished by a circular edge weld of the lid to the housing. The changeover from TIG welding to laser welding reduced the original cycle time of $14 \mathrm{sec}-$ onds by a factor of 10 to 1.4 seconds.

Two years later, Elbe (Ludwigsburg, Germany) started laser welding of aluminium steering shafts for BMW. They use a $6 \mathrm{~kW}$ Trumpf $\mathrm{CO}_{2}$ laser in a double-unit Trumpf Laser Cell. A twinspot focussing optic bars the welding keyhole from spontaneous constriction, and thereby avoids melt eruptions and blow holes. The 6000 type alloy requires the application of filler wire in order to avoid hot crack formation. The manufacturing system is equipped with an optical triangulation sensor for control of concentricity and gap, seam tracking and weld bead measurement. The welded shafts have to bear a static torque of $260 \mathrm{Nm}$ and the fatigue has to exceed 600.000 load-cycle changes of $+/-70 \mathrm{Nm}$. The welded component replaced a one-piece construction and thereby allows for an economical production of several variants.

At Dura (Landsberg, Germany) a Schuler-Held dual station gantry system welds aluminium door inners for the Audi A3 with two Rofin-Sinar $2.5 \mathrm{~kW}$ Slab $\mathrm{CO}_{2}$ lasers since 1998. In the first step, the frame out of castings and extrusions is MIG welded. In the second step, covering sheets for stiffening and for carrying equipment assemblies are laser welded to the frame. The system produces 300 vehicle sets per day.

\subsection{A paradigm for innovation}

A genuine example for automotive product innovations by new product design and fabrication techniques has been introduced by Daimler-Benz in their Hamburg plant in 1997. They invented an air-space insulated exhaust manifold in a stainless steel half-shell design (fig. 5). In comparison to conventional cast-iron manifolds, this approach reduces thermal losses (superseding heat shields), warmup time (improving cold starting behaviour), weight (by a factor of three) and production costs. Minimum distortion and excellent gas-tightness are additional features of the laser welded manifold. The inner tubular sections are fabricated by hydroforming and laser cutting. The produc-
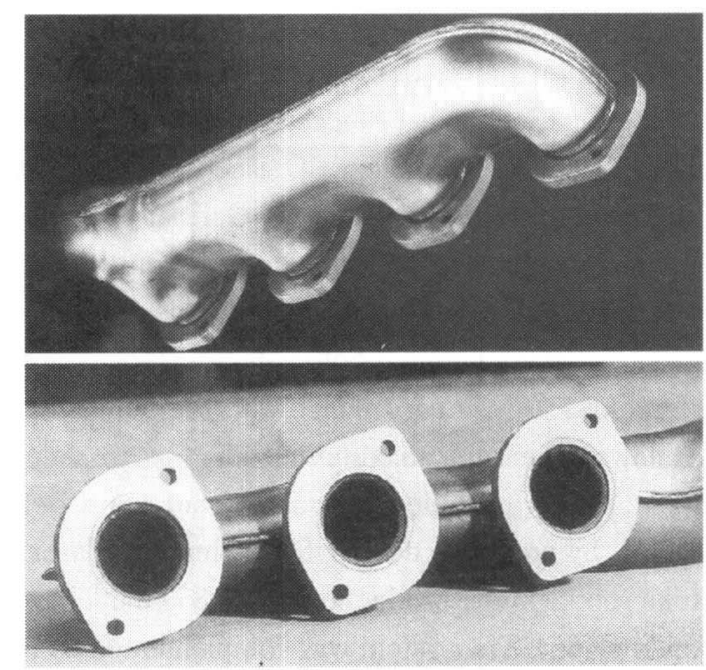

Fig. 5 Laser welded air-space insulated exhaust manifolds for V6-engines of MercedesBenz cars (source: DaimlerChrysler)

tion system in the Hamburg plant consists of 4 Trumpf Laser Cells, two of them for joining the half-shell structures and the internal tube sections and the other two stations for completing the assembly with the cylinderhead flanges.

\subsection{Wide acceptance of laser welding in European car manufacturing}

It is impossible to report within this article on all automotive laser joining achievements of the following years up to now, and even by concentrating on pioneer work there are still numerous applications to be mentioned. The reader may understand, that only a selection can be presented here. In 1998 Volvo announces an accumulated production of 2.3 Mio vehicles with laser welded roofs. Also in France, laser welding applications in the body shop became more accepted, e.g. at Peugeot for joining the rocker rail to the floor panel of the 306 model and at Renault to join the Apillars, the roof and the front cross member of the Laguna model. In both plants, $3 \mathrm{~kW} \mathrm{Nd:YAG} \mathrm{lasers} \mathrm{are} \mathrm{applied.}$

\subsection{Laser brazing}

At the same time, Audi (Ingolstadt, Germany) continued the track record of lasers in automotive manufacturing by pioneering the first laser brazing on the galvanised outer body skin of their TT coupe. The C-pillars are brazed to the rear body sides with two $1 \mathrm{~kW} \mathrm{Nd:YAG} \mathrm{lasers} \mathrm{and} \mathrm{two}$ 6-axis robots, using a silver-bearing brazing filler alloy for the $330 \mathrm{~mm}$ long seams. High strength due to the large joint face, excellent visual appearance of the seam and preservation of the corrosion resistance of galvanized components are important characteristics of the process. Presently, laser brazing of car body components is a widely used state-of-the-art process, particularly for joining tasks at trunk lid and roof at various car manufacturers, e.g. the trunk lid of the Audi A4 (2000), the roof to side joint of the Renault Laguna II (2001), the trunk lid of DaimlerChrysler's Mercedes E series T model (2002) and Mercedes SLK 
series (2004), the trunk lid of BMW 5 series and the Opel Vectra Caravan and roof and trunk lid of the Audi A3 series as well as of the VW Golf V (the latter all 2003).

\subsection{More aluminium welding}

In 1999, Audi (Neckarsulm, Germany) established a new record by introducing the $\mathrm{A} 2$ model, the first high-volume car with a complete aluminium body and structure including $30 \mathrm{~m}$ laser weld seam length (fig. 6). Sixteen $3 \mathrm{~kW}$ Nd:YAG lasers from Trumpf (then Haas) are mainly used for overlap joining of sheet panels to the frame structure at the underbody, the side, the roof and the doors. The single seam lengths vary between 35 and $800 \mathrm{~mm}$, joining mainly sheet metal to extrusions, but also cast parts to extrusions. This is for sure a famous milestone in automotive lightweight construction. Nevertheless, most of the recent car concepts emphasize a mixed-material approach, in order to economically resolve the conflict of interests in light weight, as well as in passenger safety and comfort.

Current laser welding applications on aluminium components include

- a reinforcement part in the front end of the new BMW 3 series cabriolet produced from two sheets combined in a lap joint configuration by 44 stitch welds(2000),

- the hood of the Renault Laguna II (2001),

- the laser-MIG hybrid welding of roof to side parts and various laser welds of floor panel and side panel to the spaceframe of the new Audi A8 with five $4 \mathrm{~kW}$ diodepumped Nd:YAG lasers from Rofin (2002),

- the doors of the Maybach 57 and 62 model of DaimlerChrysler, welded with a $4 \mathrm{~kW}$ Nd:YAG laser from Trumpf (2002),

- the doors of the VW Phaeton including laser-MIG hybrid and pure laser welds (2002)

- and the body front end of the BMW 5 and 6 series with the cross member laser welded to the bulkhead and brackets to the cross member (2003).

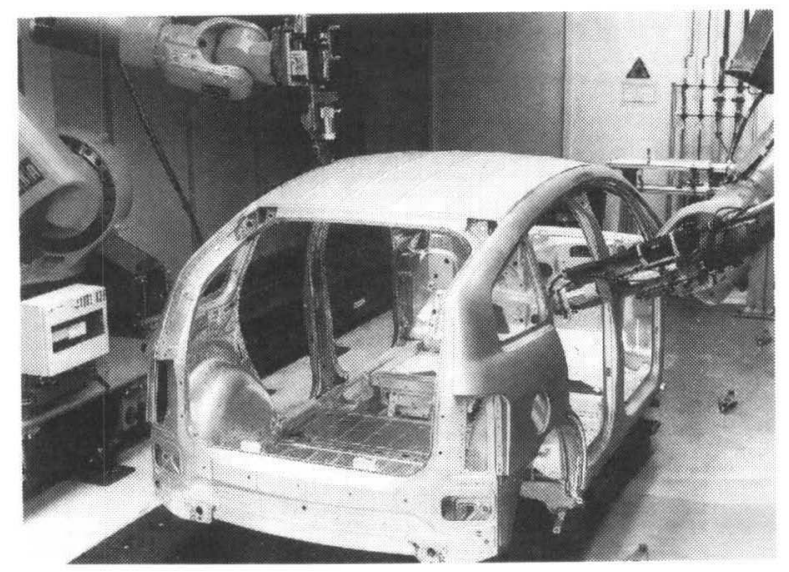

Fig. 6 Laser welding the aluminium body (here: roof seam and C-pillar) of the Audi $A 2$ in the body shop with 6-axis Kuka robots. fibre-coupled with Trumpf $3 \mathrm{~kW}$ Nd:YAG lasers (source: Audi).

\subsection{Laser-MIG hybrid welding}

The above-mentioned laser-MIG hybrid welds on the Audi A8 roof and the VW Phaeton doors are the first published laser-arc hybrid applications in automotive serial production. By the combination of a deep-penetration welding laser beam and a gap-bridging MIG-process, the laser can open up a substantially extended range of applications in modern car production not only on aluminium parts but also on high-strength steel components.

\subsection{Fillet weld at lap joint}

Zinc coated steel components are laser welded increasingly with a fillet weld at lap joint at the edge of the upper sheet - sometimes also called edge joint. Thereby, in comparison to standard lap welds through both sheets, improvements regarding welding speed, quality, quality inspection, sealing and corrosion resistance respectively, styling possibilities and fatigue are achieved. On the other hand, this joint configuration requires accurate positioning of the laser spot relative to the edge, in most practical cases only to be guaranteed with a seam tracking sensor and a closed-loop control of machine axes. Examples are the $\mathrm{CO}_{2}$ laser welding of the side panel to the rocker rail of the BMW 3 series cabriolet (2000), roof seam welding with a Nd:YAG laser on the Volvo XC90 model (2001), the laser welded front header panel of the DaimlerChrysler Mercedes E series (2001) and components of a retractable hardtop, welded with a diode-pumped Nd:YAG laser from Rofin at Karmann, Osnabrueck, Germany (2002).

\subsection{Process and quality monitoring}

Another trend is the gradually increasing utilisation of pre-, in- and post-process sensors in the production lines. The demand of automotive manufacturers for these devices is enormous, but the features of the existing systems still have to be improved. However, first successful installations in serial production are reported e.g. for tailored blank welding. In the body shop, seam tracking and in-process quality control for roof welding at BMW and welding process monitoring at DaimlerChrysler and Audi as well as post-brazing quality control at Audi are recent examples.

\section{State-of-the-art and short outlook}

The up-to-date bench marks of automotive laser applications for sure are represented by VW in their Golf V production plants. A length of $70 \mathrm{~m}$ laser based joints per car produced with a considerable quantity of 150 Trumpf $4 \mathrm{~kW}$ Nd:YAG-lasers (merely counting the Wolfsburg installations) are just two of the numerous highlights of this production.

Presently, benefits of laser materials processing are well demonstrated and recognised in European automotive production. Lasers permit improvements concerning product properties like strength, stiffness, light weight, dimensional accuracy and durability as well as concerning production 
aspects like freedom of design, material flexibility, productivity, variant flexibility and cost efficiency.

But we did not yet reach the summit of laser supported vehicle manufacturing. In view of innovations like

- large area remote welding (fig. 7) or robot guided scanner welding,

- new laser-arc hybrid approaches, e.g. utilising a coordinated modulation of laser and arc,

- reliable process and quality monitoring systems with intelligent image processing techniques,

- combination heads allowing for an optimised temporal and spatial sequence of cutting and welding operations in one setting without tool exchange,

- compact and efficient diode laser tools for sequential as well as for single-shot processing

- and last but not least disk and fibre lasers combining short wavelength, high power and high beam quality the hitherto track record of laser applications in automotive manufacturing will be continued.

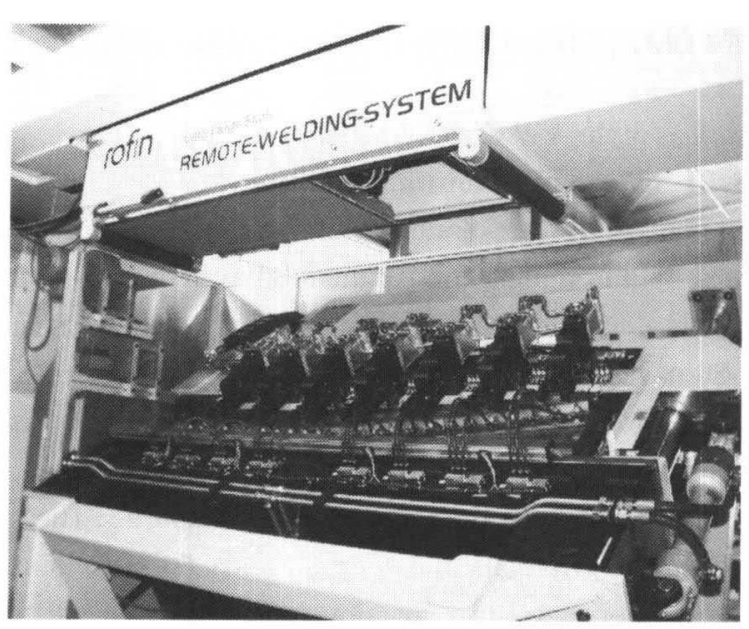

Fig. 7 Remote welding system, equipped with a Rofin $3.5 \mathrm{~kW}$ Slab $\mathrm{CO}_{2}$ laser and a customised clamping device for multi-spot welding the slide-door of the VW T5 van at the supplier Laepple. Heilbronn, Germany since 2001 (source: Rofin-Sinar). 